\title{
Epidemiology of headache in the Republic of San Marino
}

\author{
R D'ALESSANDRO, G BENASSI, P L LENZI,* G GAMBERINI, T SACQUEGNA, \\ P DE CAROLIS, E LUGARESI
}

From the Institute of Neurology, and the Institute of Human Physiology, ${ }^{*}$ University of Bologna, Bologna, Italy

SUMMARY An epidemiological survey on headache was performed in the Republic of San Marino, which is the smallest independent State in the world, located near the Adriatic Coast, within Italy. Among a random sample of 1500 inhabitants over 7 years of age the frequency of headache, severe headache and migraine in the previous year was $35 \cdot 3 \%, 12 \cdot 2 \%, 9 \cdot 3 \%$ respectively for men, and $46 \cdot 2 \%, 20 \cdot 6 \%, 18 \%$ for women. The most common factors reported to provoke headache were emotional stress, physical strain, lack of sleep, particular foods or drinks and for women menstruation. Migraine patients differed from people without headache in that they had a higher consumption of coffee, more frequently reported bad sleep, allergic disease and previous appendectomy. Furthermore, migraine patients and severe headache sufferers had a higher diastolic blood pressure than non headache subjects.

Many studies have been performed on the epidemiology of headache and migraine. Extensive reviews on the matter are available. ${ }^{1-3}$ However, no studies have been made to our knowledge, on a general population within the Mediterranean area. Here we present the results of a population survey performed in the Republic of San Marino.

\section{Methods}

The Republic of San Marino is the smallest independent State in the world, located near the Adriatic Coast, within Italy. It is 22 square miles ( 57.2 square $\mathbf{k m})$ in area. On 31 December, 1984 there was a population of $21,792,10,893$ men and 10,899 women. The Republic is dominated by Mount Titano, 2460 feet above sea level. Most of the population live in San Marino, a mediaeval town on Mount Titano or in eight small villages spread over the territory. The Republic is therefore divided into nine zones, named "castles", according to each village and the town. A systematic random sample of 1500 inhabitants over 7 years of age was obtained from official records. Each subject was then invited by letter to present himself at the social centre of his castle to answer a questionnaire administered by two trained interviewers. The questionnaire was divided into eight parts.

Address for reprint requests: Roberto D'Alessandro, MD, Clinica Neurologica, Via U. Foscolo 7, 40123 Bologna, Italy.

Received 27 March 1987. Accepted 15 June 1987
The first three parts concerned general demographic findings, life habits and past medical history. The first question of the fourth part was: "Do you suffer or have you suffered over the past year from headache?" In the case of an affirmative answer the questionnaire was completed. Otherwise people were asked if they had suffered from headache in the past and if such headache was frequent or rare, at which age it had begun and ended and the questionnaire was stopped. Blood pressure was taken with a standard mercury manometer on the right arm, with the subject sitting, at the end of the third part of the questionnaire and before the first question of the fourth part. Interviewers were trained at the Headache Centre of our Clinic where they interviewed together 50 patients with headache under the supervision of a physician expert on headache. Subsequently they did 80 cross-interviews to volunteer inhabitants of San Marino encountered in government offices and 20 children in primary and junior schools. Agreement between the two interviewers ranged from $76 \%$ to $100 \%$ depending on single items. Agreement between the two interviewers on the major questions is shown in table 1 . Among people who answered the questionnaire a random sample of 80 suffering from headache were invited to come forward to be interviewed and examined by a neurologist expert on headache. Sixtyone of them agreed to be examined. All 42 people who answered affirmatively to question No 65 were also interviewed (personally or by telephone) by two of us in order to ascertain classic migraine cases.

Among 346 people who refused to answer the questionnaire we interviewed 169 ( 84 men, 85 women) of them by telephone, asking if they suffered from headache and its severity. Distribution by age and sex of the whole popu- 
Table 1 Main questions concerning headache and agreement between answers obtained by two interviewers

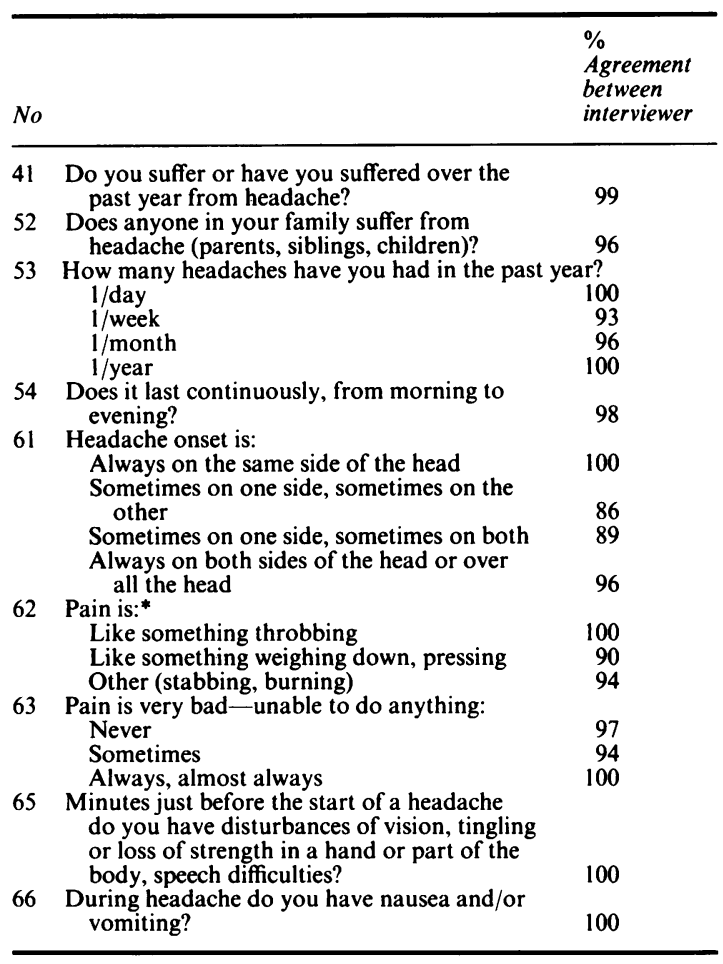

*More than one answer was possible.

lation of the Republic of San Marino, the initial sample and people interviewed by questionnaire and by telephone are shown in table 2 . The survey was performed from 1 July 1983 to 30 June 1984.

\section{Definitions}

Severe headache was recorded when people answered affirmatively (sometimes or always) to question No. 63 . Common migraine was defined basically according to the
Ad Hoc Committee ${ }^{4}$ when people reported at least two of positive family history, unilateral onset of pain (sometimes or usually) and nausea or vomiting during attacks (questions Nos. 52, 61, 66). Furthermore, in order to include only patients with recurrent attacks separated by free intervals we excluded patients with daily or continuous headache (questions Nos. 53, 54). Such diagnoses of severe headache and common migraine based on answers to questionnaire were compared with the final clinical diagnosis made by a neurologist on 61 people reinterviewed. As for severe headache, sensitivity was 0.95 and specificity 1.0 , whereas for common migraine, values were 0.70 and 0.83 respectively. Results of the comparison between diagnosis made on the basis of the questionnaire and by the neurologist are shown in table 3 . Any attempt to increase the specificity of the questionnaire by changing diagnostic criteria (for example, excluding positive family history) resulted in a severe loss of sensitivity. Discriminant analysis between migraine and non-migraine headache, including positive family history, onset of pain, quality of pain, nausea or vomiting and severity of pain, resulted in a higher severity of pain in the migraine group as the only significant discriminant factor.

Classic migraine was diagnosed by a neurologist, according to the Ad Hoc Committee, ${ }^{4}$ on the basis of direct interview.

\section{Results}

\section{Prevalence of headache}

Of 1500 people sampled, $1144(76 \cdot 3 \%)$ agreed to be interviewed. Among these $528(46 \cdot 15 \%)$ reported that they had suffered from headache during the preceding year. Two hundred and nineteen $(19.6 \%)$ said their headache was severe, while in 185 cases $(16 \cdot 1 \%)$ the diagnosis of common migraine was made. Among $\vec{c}$ people interviewed by telephone, $46(27 \cdot 2 \%)$ reported headache during the preceding year, $11.6 .5 \%)$ severe headache and in $12(7 \cdot 1 \%)$ common migraine was diagnosed. On the basis of this information we estimated the frequency of headache, severe headache and migraine in the whole sample was $35 \cdot 3 \%, 12 \cdot 2 \%$, $9 \cdot 3 \%$ for men and $46 \cdot 2 \%, 20 \cdot 6 \%, 18 \%$ for women respectively. Distribution by age and sex is shown in

Table 2 Whole population, initial sample, people interviewed by questionnaire or telephone, by age and sex

\begin{tabular}{|c|c|c|c|c|c|c|c|c|}
\hline \multirow[b]{2}{*}{$\operatorname{Age}(y r)$} & \multicolumn{2}{|c|}{ Whole population } & \multicolumn{2}{|c|}{ Initial sample } & \multicolumn{2}{|c|}{ Questionnaire* } & \multicolumn{2}{|c|}{ Telephonic interview } \\
\hline & $\begin{array}{l}\text { Men } \\
N \quad(\%)\end{array}$ & $\begin{array}{l}\text { Women } \\
N \quad(\%)\end{array}$ & $\begin{array}{l}\text { Men } \\
N \quad(\%)\end{array}$ & $\begin{array}{l}\text { Women } \\
N \quad(\%)\end{array}$ & $\begin{array}{l}\text { Men } \\
N \quad(\%)\end{array}$ & $\begin{array}{l}\text { Women } \\
N \quad(\%)\end{array}$ & $\begin{array}{l}\text { Men } \\
N \quad(\%)\end{array}$ & $\begin{array}{l}\text { Womeñ } \\
N \quad 1 \% \\
0\end{array}$ \\
\hline $\begin{array}{l}7-10 \\
11-15 \\
16-20 \\
21-25 \\
26-30 \\
31-40 \\
41-50 \\
51-60 \\
61-70 \\
\geqslant 71 \\
\text { Total }\end{array}$ & $\begin{array}{c}617(6) \\
965(9 \cdot 6) \\
1014(10 \cdot 1) \\
894(9) \\
809(8) \\
1566(15 \cdot 6) \\
1418(14) \\
1224(12 \cdot 2) \\
919(9 \cdot 2) \\
592(6) \\
10015(100)\end{array}$ & $\begin{array}{c}617(6) \\
877(8 \cdot 6) \\
933(9 \cdot 2) \\
876(8 \cdot 6) \\
832(8) \\
1575(15) \\
1374(13 \cdot 5) \\
1243(12 \cdot 2) \\
986(9 \cdot 8) \\
774(7 \cdot 6) \\
10151(100)\end{array}$ & $\begin{array}{c}25(33) \\
66(6 \cdot 6) \\
77(10) \\
80(10 \cdot 4) \\
55(7 \cdot 2) \\
123(16) \\
103(13 \cdot 5) \\
107(14) \\
73(9 \cdot 5) \\
55(7 \cdot 2) \\
763(100)\end{array}$ & $\begin{array}{c}29(4) \\
77(10) \\
72(9 \cdot 7) \\
66(8 \cdot 9) \\
50(6 \cdot 8) \\
99(13 \cdot 4) \\
91(12 \cdot 3) \\
103(13 \cdot 8) \\
91(12 \cdot 3) \\
61(8 \cdot 2) \\
737(100)\end{array}$ & $\begin{array}{l}21(3 \cdot 7) \\
51(9) \\
61(10 \cdot 8) \\
54(9 \cdot 6) \\
42(7 \cdot 5) \\
79(14 \cdot 07) \\
73(13) \\
86(15 \cdot 3) \\
53(9 \cdot 4) \\
42(7 \cdot 4) \\
562(100)\end{array}$ & $\begin{array}{l}27(4 \cdot 6) \\
64(11) \\
56(9 \cdot 6) \\
47(8) \\
35(6) \\
76(13) \\
71(12 \cdot 2) \\
89(15 \cdot 2) \\
69(11 \cdot 8) \\
49(8 \cdot 4) \\
582(100)\end{array}$ & $\begin{array}{c}- \\
8(9 \cdot 5) \\
6(7 \cdot 1) \\
13(15 \cdot 4) \\
5(5 \cdot 9) \\
16(19) \\
11(13) \\
10(11 \cdot 9) \\
10(11 \cdot 9) \\
5(6) \\
84(100)\end{array}$ & 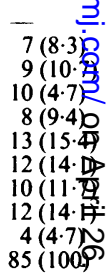 \\
\hline
\end{tabular}

*Ten people were not able to answer the questionnaire because of some kind of handicap. 
Table 3 Comparison of diagnosis of migraine obtained by questionnaire and by clinical interview

\begin{tabular}{llc}
\hline & \multicolumn{2}{l}{ Questionnaire/clinical interview } \\
\cline { 2 - 3 } & Migraine & Non migrainous headache \\
\hline Migraine & 26 & 4 \\
Non migrainous head & 11 & 20 \\
\hline
\end{tabular}

the fig. It can be seen that severe headache and common migraine show a similar trend, with a higher frequency among 41-50 year old men and among 31-60 year old women, and a rapid fall in frequency after 60 years of age in both sexes.

The differences in frequency of severe headache and common migraine between the two sexes were particularly evident among $31-60$ year old people. No significant differences were found in frequency of severe headache and common migraine as far as education, work and marital status were concerned.

Classic migraine was confirmed in 12 people (seven females, five males) out of 42 who reported visual or other disturbances before headache. Most false positive cases were common migraine patients with non specific visual disturbances before or during attacks. No subjects with a headache suggesting classic migraine were found among people interviewed by telephone. Therefore the estimated prevalence of classic migraine in our sample was $0.6 \%$ for men, and $0.9 \%$ for women.

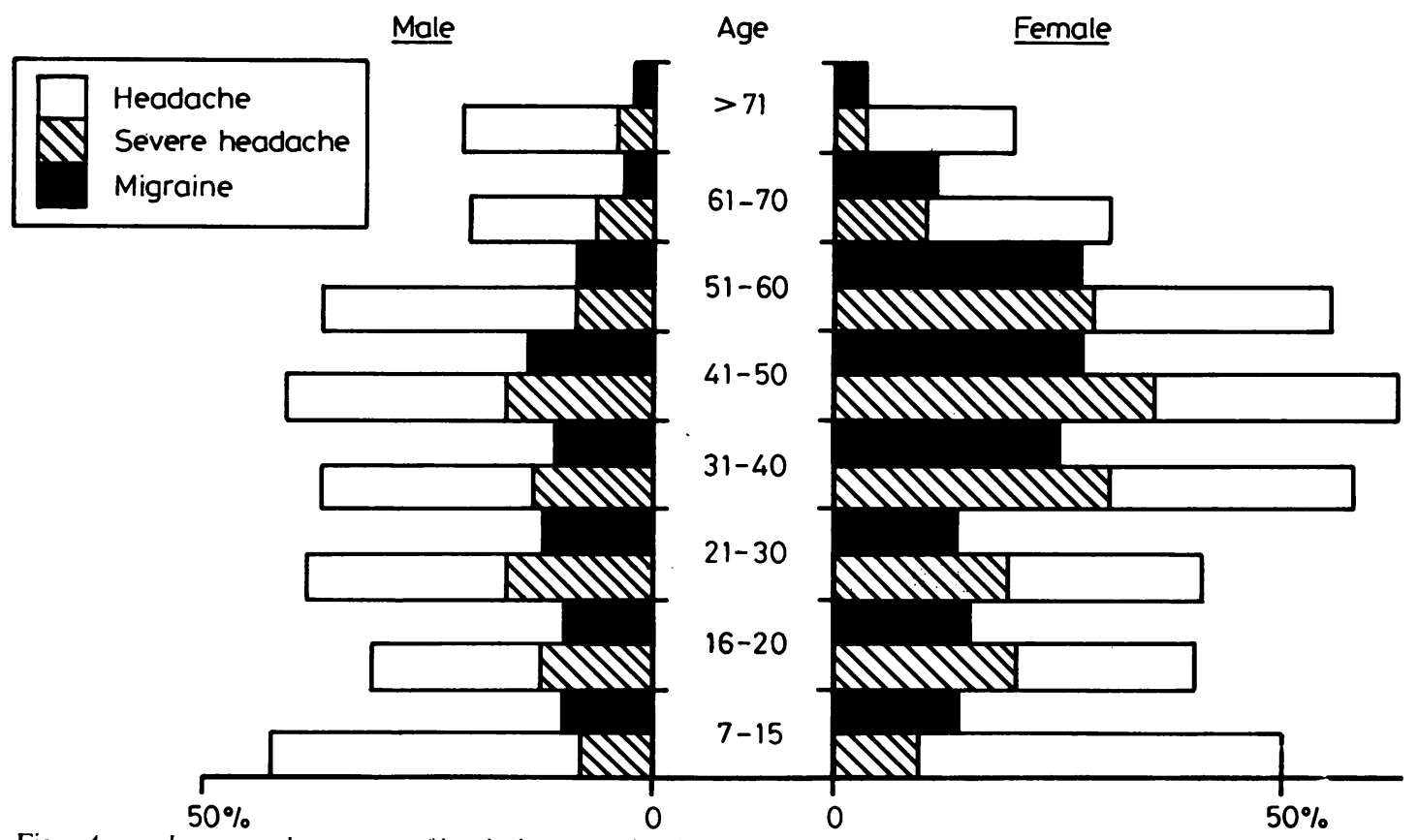

Factors provoking headache

As shown in table 4, the most common factors provoking headache among people who answered the questionnaire are emotional stress, physical strain, lack of sleep, particular foods or drinks (cheese, chocolate, tea, etc) and for women, menstruation.

There are also miscellaneous other factors, comprising cigarette smoking, weather changes, sinusitis, noise, etc. By comparing factors provoking headache among people with severe headache and with mildmoderate headache, we found that among men the difference was statistically significant for particular foods, drinks and other factors (mainly cigarette smoking) whereas among women, significantly related to severe headache were emotional stress, physical fatigue, lack of sleep and menstruation.

\section{Migraine, life habits and past medical history}

We compared people with migraine and people without headache concerning lifestyle and some aspects of medical history (table 5). In order to verify whether the two groups differed we used stepwise discriminant analysis ${ }^{5}$ including age and sex as independent variables. As one can see (table 6), migraine patients differ significantly, with a higher consumption of coffee, more frequently reported bad sleep, allergic diseases (asthma, hay fever, skin eczema) and previous appendectomy. 
Table 4 Factors blamed for provoking headache

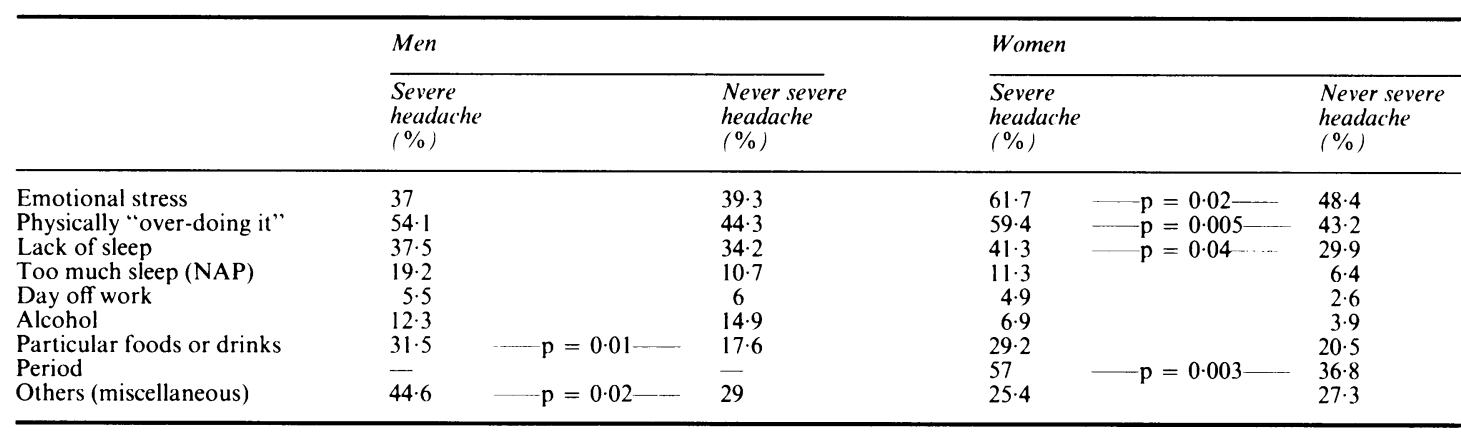

*People interviewed with questionnaire.

(p from $\chi^{2}$ Test).

Headache and blood pressure

In seven out of nine "castles" blood pressure was determined in people over 15 years of age (879 subjects). People were divided according to answers in different groups. Differences among the means were evaluated by the Analysis of Covariance. As categorical independent variables (factors), different headache groups were selected (table 7). As metric independent variables (covariates), age and Body Mass Index (BMI) were considered (BMI = weight $/$ height $^{2}$ ). As dependent variables, diastolic and systolic arterial pressure were finally taken into account. By this procedure, differences among means

Table 5 Migraine, life habits and medical history

\begin{tabular}{|c|c|c|}
\hline & $\begin{array}{l}\text { No headache } \\
(N=603) \\
(\%)\end{array}$ & $\begin{array}{l}\text { Migraine } \\
(N=185) \\
(\%)\end{array}$ \\
\hline \multicolumn{3}{|l|}{ Cigarette smoking: } \\
\hline Never & $73 \cdot 6$ & $71 \cdot 1$ \\
\hline $1-10$ day & 11.6 & $11 \cdot 8$ \\
\hline $11-20 /$ day & $9 \cdot 5$ & $12 \cdot 8$ \\
\hline $21-40$ day & $4 \cdot 6$ & $3 \cdot 2$ \\
\hline$>40 /$ day & $0 \cdot 7$ & $0 \cdot 2$ \\
\hline \multicolumn{3}{|l|}{ Alcohol: } \\
\hline Never & $42 \cdot 9$ & $42 \cdot 2$ \\
\hline $\begin{array}{l}\text { Less than } 1 \text { It wine/day and/or } \\
\text { rarely spirits }\end{array}$ & $54 \cdot 5$ & $56 \cdot 1$ \\
\hline $\begin{array}{l}\text { More than } 1 \text { lt wine/day and or } \\
\text { usually spirits }\end{array}$ & $2 \cdot 7$ & 1.6 \\
\hline \multicolumn{3}{|l|}{ Coffee: } \\
\hline Never & $42 \cdot 5$ & $36 \cdot 4$ \\
\hline Less than 3 day & 51.7 & $50 \cdot 3$ \\
\hline More than 3 day & $5 \cdot 8$ & 13.4 \\
\hline Bad sleep & $15 \cdot 8$ & $24 \cdot 1$ \\
\hline \multicolumn{3}{|l|}{ Use of sleeping pills: } \\
\hline Never rarely & $96 \cdot 7$ & 91.9 \\
\hline Often & $1 \cdot 3$ & $4 \cdot 8$ \\
\hline Always & 2 & $3 \cdot 2$ \\
\hline Allergic disease & $17 \cdot 9$ & $27 \cdot 9$ \\
\hline High blood pressure & $9 \cdot 7$ & $11 \cdot 3$ \\
\hline Myocardial infarction & $0 \cdot 8$ & 1.6 \\
\hline Stomach ulcer & $7 \cdot 1$ & $7 \cdot 5$ \\
\hline Appendectomy & $12 \cdot 1$ & $20 \cdot 3$ \\
\hline Cholecystectomy & 1.7 & $1 \cdot 1$ \\
\hline
\end{tabular}

were evaluated after removing from the dependent variable the variation due to covariates. The statistical significance of differences among means was assessed by the modified $t$ test associated with the Bonferroni method. ${ }^{6}$ In table 7 significant differences are indicated (for $p<0.05$ ). Diastolic blood pressure was higher in the "migraine" group than the "no headache" group, in both men and women (table 7). Only in women was this pressure higher in the "headache with nausea and vomiting" group than in the "headache without nausea and vomiting" group. In both men and women diastolic arterial pressure was higher in the "headache always severe" group than in the "headache never severe" group.

\section{Discussion}

There are many published studies on the prevalence of headache. However, this is the first investigation performed in a general population in South Europe. In order to make it comparable with other studies we decided to give the prevalence figures both for severe headache and migraine. Furthermore, we decided to ascertain diagnosis in all people with a possible classic migraine. In fact, severe headache is a social health

Table 6 Migraine, life habits and medical history. Results of discriminant analysis (versus no headache group)

\begin{tabular}{lccc}
\hline $\begin{array}{l}\text { Variables } \\
\text { entered }\end{array}$ & $\begin{array}{l}\text { Discriminant } \\
\text { function } \\
\text { coefficients }\end{array}$ & Partial $F$ & $p$ \\
\hline Sex & 1.353 & 26.0 & $<0.01$ \\
Age & -0.0214 & 10.4 & $<0.01$ \\
Cigarette smoking & 0.179 & 1.3 & $\mathrm{NS}$ \\
Coffee & 0.611 & 7.7 & $<0.01$ \\
Bad sleep & 0.782 & 4.5 & $<0.05$ \\
Sleeping pills & 0.534 & 1.6 & $\mathrm{NS}$ \\
Allergic diseases & 0.546 & 8.1 & $<0.01$ \\
Appendectomy & 0.773 & 4.3 & $<0.05$ \\
Constant & -4.245 & & \\
\hline
\end{tabular}


Table 7 Age and blood pressure (average $+S D$ ) in different groups

\begin{tabular}{|c|c|c|c|c|}
\hline & $N$ & Age (yr) & $D B P$ & $S B P$ \\
\hline \multicolumn{5}{|l|}{ Men: } \\
\hline No headache & 209 & $40 \pm 21$ & $81 \pm 15$ & $134 \pm 23$ \\
\hline Headache & 99 & $35 \pm 17$ & $82 \pm 15$ & $129 \pm 19$ \\
\hline Migraine & 48 & $35 \pm 17$ & $85 \pm 15$ & $130 \pm 21$ \\
\hline Headache without & & & & \\
\hline nausea/vomit & 108 & $34 \pm 17$ & $80 \pm 14$ & $128 \pm 20$ \\
\hline $\begin{array}{l}\text { Headache with } \\
\text { nausea/vomit }\end{array}$ & 38 & $39+15$ & $88+15$ & $136+21$ \\
\hline Headache never severe & 98 & $36 \pm 17$ & $82 \pm 15$ & $130 \pm 21$ \\
\hline Headache something sever & re 34 & $32 \pm 15$ & $82 \pm 16$ & $* 128 \pm 20$ \\
\hline Headache always severe & 14 & $39 \pm 16$ & $89 \pm 12$ & $132 \pm 20$ \\
\hline \multicolumn{5}{|l|}{ Women } \\
\hline No headache & 188 & $42 \pm 23$ & $78 \pm 17$ & $130 \pm 27$ \\
\hline Headache & 136 & $38 \pm 20$ & $78 \pm 16$ & $* 127 \pm 23$ \\
\hline Migraine & 79 & $38 \pm 18$ & $81 \pm 15$ & $126 \pm 21$ \\
\hline $\begin{array}{l}\text { Headache without } \\
\text { nausea/vomit }\end{array}$ & 120 & $26+21$ & 76 & 12 \\
\hline Headache with & 129 & $5 \pm 21$ & $10 \pm 17$ & 2 \\
\hline nausea/vomit & 83 & $41 \pm 15$ & $83 \pm 13$ & $129 \pm 20$ \\
\hline $\begin{array}{l}\text { Headache never severe } \\
\text { Headache something sever }\end{array}$ & $\begin{array}{r}113 \\
\text { re } 62\end{array}$ & $\begin{array}{l}37 \pm 22 \\
39 \pm 17\end{array}$ & $\begin{array}{l}76 \pm 16 \\
80 \pm 14\end{array}$ & $\left\{\begin{array}{l}125 \pm 25 \\
* 127 \pm 17\end{array}\right.$ \\
\hline Headache always severe & 37 & $41 \pm 14$ & $85 \pm 13$ & $\int 130 \pm 19$ \\
\hline
\end{tabular}

DBP, diastolic blood pressure; SBP, systolic blood pressure.

problem while classic migraine is a well featured disorder which leaves no doubt about the diagnosis. Common migraine, on the contrary, is a separate disorder from a diagnostic point of view, whose borderlines with tension headache and so-called mixed forms are ill-defined. Thus comparison with other studies on the prevalence of common migraine is difficult, since even slight changes in definition criteria (for example, pain always unilateral or sometimes unilateral) may lead to gross changes in sensitivity and specificity of the questionnaire. In our study, we tried to obtain a good specificity with a fairly good sensitivity, in order to avoid on the one hand the inclusion of too many false positive cases and on the other, the use of ambiguous terms such as "other vascular headaches". Discriminant analysis showed in our study that the main factor distinguishing between migraine and non migrainous headache is the intensity of pain. This finding agrees with other previous studies showing that the number of migraine features increases with the severity of pain. ${ }^{7}$ However, we abandoned the idea of giving an operational definition of migraine as "recurrent severe headache" and decided to accept the best compromise possible with the definition of common migraine used in our questionnaire (sensitivity 0.70 and specificity 0.83 ) to give a description of the prevalence of migraine in our population.

The prevalence of headache in our study, although lower than that found in other reports, ${ }^{8-12}$ shows that headache is a very common symptom in the Republic of San Marino.
For severe headache, our figures are lower than those found by Ziegler ${ }^{9}$ in the USA, who, however, considered together severe ("in which subjects were able to carry on some work but with difficulty"), and disabling ("completely unable to perform work") headache, and those found by Nikiforow and Hokkanen ${ }^{10}$ in Northern Finland, who, however, did not report the definition criteria of severe headache.

An indirect validation of our definition of "severe" headache is the finding that we previously reported in a paper on economic loss due to headache: ${ }^{12}$ among 514 working people, $29 \%$ of those reporting severe headache sometimes or always had lost at least one working day in the previous year whereas the same was true only for $0.5 \%$ of those reporting that their headaches were never severe. Even reducing our figures to this percentage, we found that the prevalence of severe headache is $4.7 \%(3.5 \%$ for men and 5.9 for women). Comparison of our figures with those found by Ziegler et al in China ${ }^{13}$ obtained as lifeprevalences (and not as year-prevalence as in our study) of a headache severe enough to decrease activity by at least $50 \%$ shows that severe headache is more common in the Republic of San Marino, suggesting that social, environmental and genetic factors play a relevant role in determining severe headache onset.

The prevalence of common migraine in our study is similar to that found by Waters ${ }^{14}$ and Waters and $O^{\prime}$ Connors ${ }^{8}$ in England, Nikiforow in Finland ${ }^{15}$ and Markush $^{16}$ in the USA. Recently, Bruyn, ${ }^{17}$ reviewing reports on the epidemiology of migraine, stressed the many problems which may in some way bias results. However, in our study we validated the diagnosis of common migraine made by our questionnaire, and this confirms that most of our patients have de facto a common migraine. Furthermore, we probably lost many other patients with a poorly featured common migraine. Therefore we cannot agree with Bruyn who concluded that a realistic percentage of migraine sufferers among populations is $1 \cdot 5-2 \%$. Such a percentage is, on the contrary, realistic for classic migraine, whose prevalence may be better compared among different populations. However, attention should be paid, in our experience, to ascertain cases since many common migraine sufferers report non specific visual disturbances without the typical temporal pattern of classic migraine aura.

Markush et $a l^{16}$ found $9 \cdot 1 \%$ of 451 women answered affirmatively to the question "does your vision blur or flicker just before the headache comes on?" However, they did not check whether an affirmative answer corresponded to a typical aura. Nikiforow ${ }^{15}$ found $5 \cdot 5 \%$ (2\% for men and $8 \%$ for women) of classic migraine among a sample of 200 people in Finland. However, this sample represented 
$80 \%$ of people requesting examination by a neurologist, selected among $\mathbf{7 6 . 8 \%}$ of the general population who originally responded to the survey. Therefore this percentage may be considerably reduced when applied to the whole population. The prevalence of classic migraine in our study is quite similar to that found by Manzoni et $a l^{18}$ among hospital staff, thus confirming that its value is around $1 \%$ in our region. This finding suggests that further studies should be performed on large samples in order to verify whether classic migraine has different prevalence rates among other populations.

Distribution by age and sex of migraine and severe headache in our population duplicates findings from most similar studies. We would stress two findings: (1) migraine and severe headache have a similar distribution by age, supporting again the probability that most recurrent severe headaches are de facto migraine headache; (2) the increase in frequency of migraine and severe headache among women is particularly striking after 30 years of age. This finding suggests that puberty probably plays a minor role in the sex differential whereas pregnancy and childbirth, which may facilitate the appearance of migraine headache, as we previously reported ${ }^{13}$ may play a major role in increasing the frequency of both severe headache and migraine in women over 30 . This finding is also supported by the long term changes in hormonal environment induced by pregnancy. ${ }^{20} 21$

Factors blamed for headache seem to differ between the sexes and between people with severe headache and people who never have severe headache. In women, emotional and physical stress, lack of sleep, and menstruation seem more related to the occurrence of severe headache, whereas in men this applies to dietary factors and miscellaneous other factors (mainly cigarette smoking and weather changes). Stress is also the commonest factor in other studies, ${ }^{10}$ and our values are similar to those found in the Finnish population. Dietary factors, on the contrary, seem far more common in our population than in the studies of Paulin et $a l^{11}$ and Nikiforow and Hokkanen, ${ }^{10}$ where they were reported by $4 \%$ of headache sufferers. Whether this is a true difference or an over reporting of such factors in our population cannot be stated. However, changes in the frequency of provoking factors (particularly stress) among populations with different social, cultural and dietary customs may explain differences in the frequency of severe headache. Migraine sufferers seem to differ from people without headache in some of their lifestyle and past medical history. Higher coffee consumption among migraine patients may be explained by the beneficial effect that caffeine has on migraine. ${ }^{22}$ Bad sleep is probably related to psychological disturbances which are frequently found among migraine patients. ${ }^{23}$ However, lack of sleep has also been reported as a provoking factor by a number of patients with severe headache in our study. This relationship between sleep disturbances and severe headache and migraine has not been previously stressed and further studies shovild be performed to verify whether sleep disturbance treatment may also improve headache in this subgroup of patients.

The association of migraine with allergic diseases in our study is in agreement with previously reported epidemiological findings of Ziegler ${ }^{9}$ and with studies by Maural $e t a l^{24}$ and Egger $e t a^{25}$ on food allergy among migraine patients. These findings suggest that an allergic mechanism may be operative in migraine.

The curiously more frequent appendectomy among migraine patients is difficult to explain. The most likely explanation is that migraine patients may have suffered in infancy from recurrent abdominal pain, that is considered to be an "equivalent" of migraine in childhood, ${ }^{26}$ and because of this they more frequently underwent appendectomy.

The relationship between headache and blood pressure has been the subject of numerous studies giving controversial results. Walker, ${ }^{27}$ in his general practice population of 5785 patients, found in those suffering from migraine significantly higher systolic andP diastolic blood pressure, whereas Waters, ${ }^{28}$ in a com $\cong$ munity study, did not find significant differences between patients complaining of headache oro migraine and those without headache. More recentlyo Markush $e{ }^{a l^{16}}$ found among women that migraineo is significantly associated with reported hypertension and Ziegler et $a l^{9}$ found that reported hypertensions among women is significantly associated with disabling or severe headache. In our study we did not find an association between migraine and hypertension but our patients with migraine or severe headache showed higher diastolic pressure. Although the number of differences do not have clinical implications, this finding may indicate a different cardiovascular regulation in migraine patients which may be related to their emotional reactivity.

The final picture to emerge from our results is that severe headache and migraine, which widely overlap in the general population, are disturbances for which several aetiological factors (emotional, dietary, allergic, hormonal, sleep-wake cycle disturbances) operate on the grounds of personal susceptibility. Whether these factors act in a common final way to determine headache or operate with different mechanisms is a matter for biological and clinical studies.

We thank G Morganti, Head of the Psychiatric Service of the Republic of San Marino, F Micheloni, MD, and D Manzaroli, MD, of the Health Service of the Republic of San Marino, for their valuable help, 
and A Pollini for editorial assistance. This work was supported partly by I.S.S., Republic of San Marino and by University of Bologna, grant 5419, Chap. $12 / 6$.

\section{References}

1 Leviton A. Epidemiology of headache. In: Schoenberg BS, ed. Advances in Neurology, vol. 19. New York: Raven Press, 1978:341-53.

2 Goldstein M, Chen TC. The epidemiology of disabling headache. In: Critchley M, et al, eds. Advances in Neurology, vol. 19. New York: Raven Press, 1982:377-90.

3 Ziegler DK. Epidemiology of migraine. In: Clifford Rose F, ed. Handbook of Clinical Neurology, vol. 4(48): Headache, chap. 2. Amsterdam: Elsevier Science Publishers B.V., 1986:13-22.

4 Ad Hoc Committee on Classification of Headache. Classification of headache. JAMA 1962;179:717.

5 Nie N, Hull CH, Jenkins JG, Steinbrenner WK, Bent DH. Statistical Package for the Social Sciences. 2nd ed. New York: McGraw-Hill, 1975.

6 Wallenstein S, Zucker CL, Fleiss L. Some statistical methods useful in circulation research. Circ Res 1980;47:1-9.

7 Waters WE. The epidemiological enigma of migraine. Int J Epidemiol 1973;2:189-94.

8 Waters WE, O'Connor PJ. Epidemiology of headache and migraine in women. $J$ Neurol Neurosurg Psychiatry 1971;34:148-53.

9 Ziegler DK, Hassanein RS, Couch JR. Characteristics of life headache histories in a nonclinic population. Neurology 1977;27:265-9.

10 Nikiforow R, Hokkanen E. An epidemiological study of headache in an urban and a rural population in Northern Finland. Headache 1978;18:137-45.

11 Paulin JM, Waal-Manning HJ, Simpson FO, Knight RG. The prevalence of headache in a small New Zealand Town. Headache 1985;25:147-51.

12 Benassi G, D’Alessandro R, Lenzi PL, Manzaroli D, Baldrati A, Lugaresi E. The economic burden of headache: an epidemiological study in the Republic of San Marino. Headache 1986;26:457-9.
13 Cheng X-m, Ziegler DK, Li S-c, Dai Q-s, Chandra V, Schoenberg BS. A prevalence survey of 'incapacitating headache' in the People's Republic of China. Neurology 1986;36:831-4.

14 Waters WE, O'Connor PJ. Prevalence of migraine. J Neurol Neurosurg Psychiatry 1975;38:613-6.

15 Nikiforow R. Headache in a random sample of 200 persons: a clinical study of a population in northern Finland. Cephalalgia 1981;1:99-107.

16 Markush RE, Karp HR, Heyman A, O'Fallon WM. Epidemiological study of migraine symptoms in young women. Neurology 1975;25:430-5.

17 Bruyn GW. Epidemiology of migraine "A personal view". Headache 1983;23:127-33.

18 Manzoni GC, Campari M, Terzano MG, Moretti G, Fanti E. An epidemiological study of headache in a Hospital staff. Headache 1980;21:206-10.

19 Benassi G, D’Alessandro R, Lenzi PL, Di Federico M, Cristini E, Gamberini G. Cefalea e ciclo riproduttivo femminile: indagine epidemiologica. Societa' Italiana per lo Studio delle Cefalee, IX Congresso Nazionale. Parma, 6-8 ottobre 1986. CIC edizioni internazionali 1987:165-71.

20 Musey VC, Collins DC, Musey PI, Martino-Saltzman D, Preedy JRK. Long-term effect of a first pregnancy on the secretion of prolactin. $N$ Engl J Med 1987;316:229-34.

21 Musey VC, Collins DC, Brogan DR, et al. Long term effects of a first pregnancy on the hormonal environment: estrogens and androgens. J Clin Endocrinol Metab 1987;64:111-8.

22 Berde B, Cerletti A, Dengler HJ, Zoglio MA. Studies of the interaction between ergot alkaloids and xanthine derivatives. In: Cochrane AL, ed. Background to Migraine, 3rd Migraine Symposium. New York: Springer-Verlag, 1970:80-102.

23 Crisp AH, Kalucy RS, McGuinnes B, Ralph PC, Harris G. Some clinical, social and psychological characteristics of migraine subjects in the general population. Postgrad Med $J$ 1977;53:691-7.

24 Monroe J, Brostoff J, Carini C, et al. Food allergy in migraine: study of dietary exclusion and RAST. Lancet 1980;ii:1-4.

25 Egger J, Wilson J, Carter CM, Turner MW, Soothill JF. Is migraine food allergy? A double-blind controlled trial of oligoantigenic diet treatment. Lancet 1983;ii:865-9.

26 Congdon PJ, Forsythe WI. Migraine in childhood. Dev Med Child Neurol 1979;21:209-16.

27 Walker $\mathrm{CH}$. Migraine and its relationship to hypertension. $\mathrm{Br}$ Med J 1959;ii:1430-3.

28 Waters WE. Headache and blood pressure in the community. $\mathrm{Br}$ Med J 1971;i:142-3. 